\title{
Democratic Deficits in Europe: The Overlooked Exclusiveness of Nation-States and the Positive Role of the European Union*
}

\author{
JOACHIM BLATTER, ${ }^{1}$ SAMUEL D. SCHMID ${ }^{2}$ and ANDREA C. BLÄTLLER ${ }^{3}$ \\ ${ }^{1}$ University of Lucerne ${ }^{2}$ European University Institute ${ }^{3}$ Goethe University
}

\begin{abstract}
With the help of the Immigrant Inclusion Index (IMIX), a quantitative tool for measuring the electoral inclusion of immigrants, we demonstrate that European democracies are much more exclusive than they should be. All normative theories of democracy share the conviction that it is imperative that democracies include long-term immigrant residents into the demos - either by granting citizenship or by introducing alien voting rights. But even the 20 most established and stable democracies within the EU are far from fully realizing the ideal of 'universal suffrage'. This is true independently of whether we count in- and excluded people in numerical terms, or whether we evaluate the relevant laws and regulations. Therefore, we diagnose a substantial democratic deficit on the level of European nation-states. By requiring its member states to enfranchise nonnational EU citizens on the local level, the EU, for once, plays a positive role in reducing one of the most fundamental democratic deficits in times of migration.
\end{abstract}

Keywords: democratic deficit; migration; citizenship; inclusion; exclusion; alien voting rights

\section{Introduction}

The European Union (EU) is widely believed to harbor a democratic deficit. This claim has been intensively debated in the academic literature (for an excellent overview, see Jensen, 2009). Some argue that the quality of democracy on the European level is not so bad when compared to the reality in national democracies (Crombez, 2003), but for many scholars and practitioners the sovereign nation-state is superior from a democratic point of view (Dahl, 2000; Klaus, 2014). A further allegation is that the EU is encroaching on national institutions and is undermining the functioning of national democracies - for instance, through the empowerment of the executive branch vis-à-vis the legislative branch (see Schmidt, 2006).

The first and main goal of this article is to show that European national democracies display a fundamental democratic deficit of their own. Furthermore, we show that the EU is in fact instrumental for reducing this democratic deficit. But which democratic deficit do we mean? It is instructive to start with Abraham Lincoln's famous threefold characterization of democracy as government of the people, by the people, and for the people. But in contrast to most studies using this trinity, here we do not refer to a

\footnotetext{
*This article grew out of a seminar paper that the second and third author produced in a class titled 'The Quality of Democracies and the Quality of Democracy Measurement Tools' taught by the first author at the University of Lucerne. In the long process leading to this article we had the chance to present our project at different occasions and got a lot of helpful feedback and suggestions. In this sense, we especially want to thank (in alphabetical order) Jean-Thomas Arrighi, Rainer Bauböck, Daniel Bochsler, Karima Bousbah, Marc Bühlmann, Sergiu Gherghina, Robert E. Goodin, Reinhard Heinisch, Marc Helbling, Fran Meissner and Luicy Pedroza. Furthermore, we would like to thank the JCMS referees. Finally, we thank Eva Granwehr, Samuel Huber and Paola Galano for their most helpful support with compiling the references. The dataset and further materials can be downloaded under www.unilu.ch/imix.
} 
democratic deficit in the sense of input- or output-legitimacy (government by and for the people), but rather a deficit with regard to the inclusiveness of the definition of the people themselves: the in/out-legitimacy (government of the people; see Blatter, 2007). This constitutive and therefore most fundamental issue - how to adequately define the boundaries of the demos - has recently gained increasing attention in both political practice and democratic theory (see Beckman, 2009; Benhabib, 2004; Bosniak, 2006). And in the rich academic discussion on the topic, an 'overlapping consensus' (see Rawls, 1987) has emerged: democracies should, in order to retain full legitimacy, grant voting rights to all adult, legal and long-term residents who are subjected to government coercion (see Dahl, 1989; Miller, 2008; Pettit, 2012; Rubio-Marin, 2000; Walzer, 1983).

Currently, the most significant group not included in this definition of the demos are immigrant residents. They far outnumber disenfranchised resident citizens. ${ }^{1}$ In the following, we argue that, with reference to various theories of democracy, we can deduce a strong normative demand that immigrants have to be included into the demos after five years of continuous residence. Democracies can opt to do so either by allowing immigrants to naturalize or by providing them with alien voting rights. Based on this benchmark, we develop a measurement tool for evaluating the electoral inclusiveness of democracies with respect to immigrants. The resulting Immigrant Inclusion Index (IMIX) combines existing indicators such as indices of the inclusiveness of citizenship and electoral laws, naturalization rates, and so-called 'citizenship rates' with original indicators such as the percentage of enfranchised non-citizens among all long-term immigrant residents. The results show that, among 20 established and stable democracies across the EU, in practice the ideal of a truly 'universal suffrage' is still far away. Furthermore, we demonstrate that the EU helps to reduce the exclusiveness of European nation-states by requiring that migrating EU citizens residing in other Member States have voting rights on the local level.

We are certainly not the first authors who reveal the democratic deficits of nation-states in a systematic comparative assessment (see, for example, Bühlmann et al., 2012). Also, it is not only us who point to the democracy-enhancing effects of the EU (see, for example, Keohane et al., 2009). The limited inclusion of resident immigrants is, however, still very much neglected in even the most sophisticated and up-to-date democracy measurement tools (for a critique, see Blatter et al., 2015a). Furthermore, the positive role of the EU has been acknowledged primarily for nation-states' transition towards democracy, especially when membership is offered (see Schimmelfennig and Scholtz, 2008). By contrast, our focus on the inclusion of immigrants into national demoi is not only new but also timely. In times of enormous numbers of refugees, terrorist attacks and rising nationalism, this kind of inclusion should not only be seen as a normative demand, but also as an opportunity for guiding the interactions between the sedentary population and the migrant population into peaceful channels. Moreover, while the Euro and the refugee crises are putting a heavy strain on the efficiency and legitimacy of the EU, it seems necessary to highlight that it in fact contributes to making national democracies more inclusive and thereby helps reduce one of the most serious deficits of established democracies in an age of migration, albeit in a limited way.

\footnotetext{
${ }^{1}$ Criminal disenfranchisement figures are way below 1 per cent of the population in Europe. Only in the United States they amount to about 2 per cent (Human Rights Watch, 1998).
} 


\section{Why, How, When and In Which Contexts Do Democracies Have To Include Immigrants?}

\section{Why Should Democracies Include Immigrants into their Demos?}

International migration - the flow of people across nation state boundaries - has received a lot of attention in normative political theory (see Benhabib, 2004; Bosniak, 2006; Carens, 2013). Its main strands disagree with respect to many questions surrounding this phenomenon. However, be it liberals with their guiding principles of individual autonomy and equality (Dahl, 1989, 2000; Miller, 2008; Rubio-Marin, 2000), republicans stressing the centrality of political participation for a humane life (Barber, 2003 [1984]), neo-republicans underlining the imperative of freedom as non-domination (Pettit, 2012), or even communitarians who are concerned with the constitutive functions and the cohesion of political communities (Walzer, 1983) - they all agree in principle that immigrants who have become long-time residents should be included into the demos of nation-states so that all subjected to the laws of a state can take part in creating them. Although there are differences among the various theories of democracy in respect to legitimate conditions that democracies can demand before they include immigrants (which we discuss in the following), the fact that no theory justifies the permanent exclusion of immigrants represents a kind of 'overlapping consensus' (see Rawls, 1987). This is the normative foundation for our assessment tool.

\section{How Should Democracies Include Immigrants?}

We focus on the electoral inclusion of immigrants. With this decision we follow the dominant strand in democracy measurement from its founding father, Robert Dahl, to its most recent and most sophisticated expression in the Varieties of Democracy (V-Dem) project. In Polyarchy: Participation and Opposition - a publication that served as key point of reference for virtually all approaches to measure democratization or the level/quality of democracy during the 20th century - Robert Dahl argues that the right to vote contributes to both fundamental dimensions of democracy: liberalization/contestation and inclusion/participation (Dahl, 1971, p. 4). The V-Dem project, by contrast, starts with the recognition of a plurality of normative theories of democracy. It identifies seven different understandings of democracy (such as liberal, deliberative and participatory), and develops corresponding indices. Nevertheless, electoral democracy is perceived as 'fundamental: we would not want to call a regime without elections "democratic" in any sense' (Coppedge et al., 2014, p. 4). In consequence, elections are seen as a necessary condition for a democracy, and the corresponding Electoral Component Index is part of each and every index that emerges from the V-Dem project.

\section{When Should Democracies Include Immigrants?}

Whilst democracies are normatively compelled to electorally include immigrants subjected to their rule, almost no position would demand that they unconditionally include all people who live on their territory at a certain point of time. Such a position would face the 'obvious objection [...] that it implies extending the vote to tourists and transients, 
which many regard as absurd' (Beckman and Erman, 2012, p. xiv). ${ }^{2}$ But when should immigrants be included? In the following, we first deduce an answer with reference to the core principles of divergent theories of democracy. Next, we address some potential objections.

Liberal democratic theory holds that every individual must be regarded as the best judge of her own good. Thus, 'every adult subject to the laws of the state should be considered to be sufficiently well qualified to participate in the democratic process of governing that state' (Dahl, 2000, p. 76). The only acceptable qualifications to this imperative of inclusion are that this individual is autonomous (not mentally deprived) and that she bears the consequences of her decisions (Dahl, 1989, p. 129). A pragmatic way to operationalize the latter qualification is to take the time somebody has already resided in a country as a proxy for the probability that she will stay there in the future (Bauböck, 1998).

Communitarians would object that liberalism underestimates the importance of a stable and culturally grounded political community in need of loyal members who identify with the polity. A conservative reading of this assumption would conclude that political inclusion should take place after immigrants are culturally and socially assimilated. As assimilation processes take time, rather long residency periods before inclusion would appear legitimate. Nevertheless, a more progressive view would argue that inclusion actually stimulates immigrants' identification with the polity (Fick, 2016) and therefore should take place early.

Viewing political participation both as an intrinsic good allowing living a humane life and as a precondition for the capacity of the democratic community to determine itself, classic republicanism faces a trade-off: Individual self-realization and collective selfdetermination could in principle be strengthened through an early inclusion of immigrants since this enhances the capacities of both the individual and the community. But if we assume that only those who are familiar with a political system can participate productively, it becomes apparent that some time is needed. Hence, neither immediate inclusion nor very long residency restrictions are justified. Also neo-republicans face trade-offs: Whilst, prima facie, electorally including immigrants immediately is the best way to avoid their domination by the sedentary population, this is not so evident anymore when acknowledging the multifaceted nature of current day migration. On the one hand, those migrants who escape dreadful conditions in their home country are in a vulnerable position in the country of residence, because they cannot go back easily. On the other hand, however, a growing class of wealthy mobile people use the growing rights to free movement in order to pick their country (or countries) of residence and maximize their personal well-being. To avoid unjustified domination of national communities and sedentary people by such a class of wealthy mobiles, a more restrictive approach to the electoral inclusion of immigrants seems adequate.

So, how many years should an immigrant live in a state to have a legitimate claim to inclusion? It is striking that all normative theorists who make an explicit statement about this question seem to end up endorsing a residency period of five years (see Bauböck

\footnotetext{
${ }^{2}$ We thus focus on the long-term residency requirement. Other conditions (such as language proficiency) that are applied in political practice are disputed in normative theory (Bauböck and Joppke, ).
} 
et al., 2010, p. 43; Carens, 2010, pp. 20-21; Owen, 2013, p. 331; Ruhs, 2013). ${ }^{3}$ Indeed, besides representing a decent compromise among the various positions in democratic theory outlined above, this specific time frame is defensible on several grounds. First, five years corresponds to a long legislative period. In most countries, the legislative period is only four years, but by taking the longer period, we are on the safe side for those who think that newcomers should get familiar with the functioning of a specific political system before getting the right to vote. Furthermore, a five year residency requirement makes it highly unlikely that sedentary inhabitants are dominated by mobile people who only have short-term interests in a polity; after that period, return migration is rather low (OECD, 2008). Therefore, this condition should satisfy all those who fear the inclusion of 'incompetent' or 'irresponsible' members into the demos, while it is the maximum for those who are concerned with the autonomy and non-domination of immigrants.

\section{Does the Demand to Include Immigrant Residents Depend on Context?}

In the following we discuss three possible objections to a universal demand to include immigrants. A first objection points to different circumstances that bring outsiders to a polity. Do recruited guest workers have to be treated differently than refugees? We do not think so. The contract that implicitly underlies the act of inclusion is a political rather than a social or economic one. The included person agrees to follow the laws of the state and in exchange receives the right to participate in the making of state laws. Since this contract is not a voluntary one and the migrant does not have a choice not to follow the rules of the country in which she resides, inclusion into the demos is not a gift but a right.

A second objection is concerned with different consequences for polities. Do we have to treat small countries with large groups of immigrants differently from large countries with small groups of immigrants? We do not think so. We accept the argument that established communities have a right to self-determination; and we are aware of the problem that this right might be undermined by large groups of newcomers. Nevertheless, since there are enough options for avoiding the domination of the autochthonous population by the immigrant population, a full exclusion of the latter cannot be justified. The case of Luxembourg provides a telling example. Because of its large immigrant population, the EU allows Luxembourg to derogate from the usual rule of an immediate electoral inclusion of all non-national EU citizens on the local level, and introduce residence requirements for up to five (!) years. ${ }^{4}$ Another option would be to give immigrants a special representation similar to what is the case for emigrant nationals in some countries. The votes of the non-citizens would be counted separately and a certain amount of seats in the parliament would be reserved for this group. Thereby, dominance could easily be avoided - and as the resulting inequality with respect to the weight of individual votes is nothing new in established democracies (think about the second chambers in the USA and Switzerland), it would not per se impinge upon the democratic quality of a system.

\footnotetext{
${ }^{3}$ In addition, many data sources such as the European Social Survey (ESS, 2010) or the ELECLAW indicators (EUDO CITIZENSHIP, 2015) - which we use in our analysis - use the five years threshold as a cut-off point when classifying immigrants' residence duration, which reinforces our argument from an applied empirical perspective.

${ }^{4}$ The relevant EU directives allow for a general derogation if 'the proportion of citizens of the Union of voting age who reside in [the host state] but are not nationals of it exceeds $20 \%$ of the total number of citizens of the Union residing there who are of voting age' (Lansbergen and Shaw, 2010, p. 54), and they foresee residence periods of up to five years as a counter-measure.
} 
A final objection highlights the difference between a situation in which people move and a situation in which boundaries are moved. Especially in Central and Eastern Europe, we are faced with problems of inclusion that are the result of changing boundaries which resulted in minorities with neighboring kin-states. Among normative theorists, it is disputed whether one can demand inclusive citizenship rules - for example, the acceptance of dual citizenship - in these contexts (Bauböck, 2010). For us, these concerns are convincing in those contexts in which the very existence of a country or the stability of the territorial boundary is under threat. We think that, among EU countries, this is the case in the Baltics, but not in Hungary and its neighboring states. We take this into account in our case selection.

\section{How Do We Measure the Inclusiveness of Democracies with respect to Immigrant Residents?}

Note again that the terms inclusion and inclusiveness indicate that we are concerned with the electoral inclusion of immigrants into the demos, not with their broader integration or incorporation in socio-economic or cultural terms. The wording immigrant residents signals two additional specifications. First, it indicates that conceptually we take into account all people with a migrant background, not only non-citizen residents. Second, it reminds us that the IMIX is based on the normative assumption that only those who have uninterruptedly resided in a country for at least five years have a legitimate claim to be included. ${ }^{5}$

We specify the IMIX as an index with two dimensions because there are two distinct understandings of inclusiveness: a de facto understanding for which we have to count the number of people who are actually in- or excluded; and a de jure understanding for which we have to assess the laws that regulate the access of immigrants to the demos (Blatter et al., 2015b, pp. 18-21). This distinction is important for both causal and evaluative analyses. Since the causes and consequences of the de jure inclusiveness are most probably distinct from the causes and consequences of the de facto inclusiveness, it is not appropriate to aggregate these two dimensions when using the IMIX for causal analyses. In our evaluative context, however, it is important to realise that, first of all, the two understandings have complementary strengths and weaknesses.

Intuitively, it makes sense to start an evaluation with the de facto inclusiveness. After all, the term inclusiveness implies that we want to know how inclusive a democracy actually is. This is best captured by the question: How many of those who should be included are actually included? Nevertheless, the number of those who are in- or excluded is determined by all kinds of factors, not just those that the respective polity can influence. For example, the number of naturalizations depends mostly on the rules in the country of immigration, but partly also on the rules in the country of emigration as well as on individual preferences of specific immigrants. In consequence, the de facto inclusiveness represents a reality for which the polity cannot be held fully responsible.

Looking at the rules which regulate the inclusion of immigrant residents has the advantage that it involves measuring only what is entirely determined by explicit democratic decision-making of the democracy under scrutiny. In other words, the de jure meaning

\footnotetext{
${ }^{5}$ Moreover, we stick to the traditional assumption that only adults should be included (Dahl, 1989, p. 127). Besides, we do not take into account undocumented residents due to a lack of valid data.
} 
of electoral inclusiveness expresses the will of a political community to be inclusive. Yet, measuring a specific set of rules and regulations has the disadvantage that it might miss the actual functioning of the democracy, namely when it captures only the rules in law and not the rules in use (Bühlmann et al., 2012, p. 527). For example, a country might have very lenient naturalization regulations, but the naturalization rate is still very low because there are costs and hurdles beyond the citizenship law (for example, compulsory military service or the attitude with which autochthonous residents meet immigrants; Howard, 2009, p. 24).

Given the complementary strengths and weaknesses of the de facto and the de jure understanding, we think that a comprehensive evaluation should cover both dimensions. More specifically, we argue that a rigorous evaluation would neither accept to call a democracy inclusive if its laws but not its actual functioning is inclusive, nor if the situation is characterized by a small de facto gap between those who should be included and those who are actually included but where the laws of the polity indicate no willingness to include. In more abstract terms, this means that, to fully constitute electoral inclusiveness, substitution between the two dimensions should be strictly limited, especially when one of them scores very weakly (Blatter et al., 2015b, pp. 19-21; Goertz, 2006, pp. 35-67).

The two pathways that lead to the electoral inclusion of immigrant residents - access to citizenship and alien enfranchisement - are taken up as the two components within each dimension. By access to citizenship we refer to the formal status that is granted by a state to an immigrant resident either through birthright or naturalization, and which apart from some exceptions such as the disenfranchisement of felons and/or mentally disabled persons (Paxton et al., 2003) - generally leads to electoral inclusion. The other option is to enfranchise non-citizen residents directly. Since each of the mechanisms is not a necessary but sufficient condition for achieving electoral inclusion, their relationship is one of high substitutability or family resemblance (Blatter et al., 2015b, pp. 21-24; Goertz, 2006, pp. 35-67).

We now turn to the operationalization. Within the de facto dimension we measure what we call the citizenship rate, the naturalization rate, and the alien enfranchisement rate. The citizenship rate captures the basic incongruence that exists in a country between the non-transient residents and the citizens with respect to voting rights. The latter rates capture how far this gap is reduced by the naturalization or enfranchisement of aliens. The citizenship rate is defined as the number of all adult resident citizens as a proportion of all resident adult citizens plus all adult, legal and long-term non-citizen residents (for details see appendix Ic and Id). The latter group always serves as the population that, statistically and normatively speaking, should be at risk of experiencing the event of inclusion. The naturalization rate is defined as the average number of citizenship acquisitions per year during the last 5 years ${ }^{6}$ as a proportion of all adult, legal and long-term non-citizen residents (for details see appendix Ic and Id). Finally, we measure the alien enfranchisement rate, which is defined as the number of enfranchised aliens as a proportion of all adult, legal and long-term non-citizen residents (for details see appendix Id). ${ }^{7}$

\footnotetext{
${ }^{6}$ This makes our measurement more robust and allows for a better comparison with the other, more static components.

${ }^{7}$ Unfortunately, data availability is quite limited for such indicators, which is why we cover only the registered numbers of aliens that have voting rights in legislative elections on either the local or all levels. The number in the numerator is specified in a way that is consistent with the relative weights we assign to the local and national levels for de jure alien enfranchisement (for more details see appendix Id).
} 
For the de jure dimension we analyze the respective citizenship and alien enfranchisement laws. For measuring the component de jure access to citizenship, we draw on the so-called CITLAW indicators introduced by Vink and Bauböck (2013). We calculate the average of three sub-components: ius soli, naturalization, and toleration of multiple citizenship for immigrants (cf. Howard, 2009, pp. 19-26; for details see appendix Ia). The measurement level of the resulting component is ordinal and ranges from 0 (theoretical minimum) to 100 (theoretical maximum). To gauge de jure alien enfranchisement, we use the ELECLAW indicators (EUDO CITIZENSHIP, 2015), but slightly modify the usage and aggregation of indicators (for details see appendix Ib). While covering all types of elections - legislative, presidential/executive and referenda - we only include the national and local levels of elections. The regional level is sometimes completely absent in certain countries, and entails additional complexities for coding (see Schmid et al., 2015, pp. 5-7). In addition, in the normative debate the local-national distinction is much more prominent (Pedroza 2013). The average score of the local level is combined with the score for the national level with a simple arithmetic mean as well. The normative arguments for granting alien voting rights on the local level are stronger (Bauböck, 2003), and access to citizenship is sometimes seen as the more adequate mechanism for inclusion on the national level (Bauböck, 2015). However, giving more weight to the local level would not sufficiently appreciate the higher inclusiveness of countries that indeed enfranchise non-citizen residents on the national level. Besides, for both of the two basic categories of non-citizen residents - non-national EU citizens and Third Country Nationals (TCNs) - we only consider voting rather than candidacy rights, since it is not clear how much the latter contributes to overall electoral inclusion. Again, the measurement level of this component is ordinal and ranges from 0 (theoretical minimum) to 100 (theoretical maximum).

Both the de jure components as well as the alien enfranchisement rate are plausibly scaled from 0 to 100, though the former are ordinal. By contrast, we adjust the minimum of the scale for the citizenship rate to the value of 90 per cent (corresponding to 0 on a $0-100$ scale; all values below coded as 0 ). Two of the most prominent scholars in the field of democracy measurement, Robert Dahl and Gerardo Munck, have used this value as a threshold for the identification of full-fledged democracies based on the inclusion of all long-term resident adults (Dahl, 1971, pp. 332-333, 246-248; Munck, 2009, pp. 43, 149-150). For the naturalization rate, we identify the value of 10 per cent as an ideal (corresponding to 100 on a $0-100$ scale). This is based on the following reasoning. According to our normative standards, immigrants should be included after five years. Hence, when making the counterfactual assumption that international migration takes place as a regular flow of people across state boundaries and that all immigrants stay in the new country of residence, 20 per cent of all immigrants in a country reach the required five years of stay every year and should be included. However, since we acknowledge the existence of temporary and circular migration, we adjust our ideal-typically constructed endpoint accordingly. Based on respective statistics (EMN, 2011), it seems adequate to cut back our maximum value by half, that is, from 20 per cent to 10 per cent. ${ }^{8}$ For

\footnotetext{
${ }^{8}$ For those who think our thresholds are too strict, we present alternative results using 80 per cent as the minimum citizenship rate and 5 per cent as the maximum naturalization rate in appendix IV. This scheme produces a clearly more lenient assessment with regard to national democratic deficits (though in most countries they are still glaring) and, at the same time, decreases 'EU support' (citizenship and naturalization rates are part of the national regime, and increasing their values leads to a greater impact of national measures). However, the essence of our conclusions remains unchanged.
} 
aggregation, these various (re-scaled) components are directly combined without harmonizing their measurement level, so that we can take into account their full variation. However, though the resulting score looks metric, we must treat it as ordinal (because it is a combination of percentages or linearly transformed percentages and ordinal 0-100 scales).

Our aggregation rules are as follows. To aggregate the divergent components in the respective dimensions, we apply the arithmetic mean. We do so because access to citizenship and alien enfranchisement are both sufficient conditions for including immigrants, which implies high substitutability. Furthermore, we opt for the following weights: In the de facto dimension we assign equal weights to the citizenship rate, the naturalization rate and the alien enfranchisement rate. The citizenship rate is in many ways the most fundamental criterion since it indicates the incongruence between citizenry and the long-term population. Nevertheless, since we do not want to punish those countries which have a rather open immigration policy, we should not put too much weight on the citizenship rate. The other two rates indicate how good democracies actually are at closing this basic gap between citizenry and population, either by transforming non-citizens into citizens or by expanding the boundary of the demos beyond the citizenry.

Since the citizenship rate and the naturalization rate are both sub-components of the de facto component access to citizenship, we allot a double weight to this component as opposed to alien enfranchisement. Accordingly, we also assign a double weight to access to citizenship in the de jure dimension. The first reason is that the aggregation rules should be analogous within the same level of abstraction. More importantly, however, we thereby prioritize one mechanism of inclusion. We argue that $a c$ cess to citizenship has to be prioritized if we follow dominant readings of divergent theories of democracy since it provides immigrants with a more secure status (for a more detailed reflection on this issue, see Blatter et al., 2015b, pp. 21-24, 40-44). In our first application of the IMIX, therefore, we allot greater weight to the access to citizenship. Finally, we aggregate the de jure and the de facto dimension by applying the geometric mean. This is in line with our argument that compensation between the two dimensions should be severely limited. ${ }^{9}$ The following table summarizes components and aggregation rules of the IMIX (Table 1).

\section{How Inclusive are European Democracies with respect to Immigrant Residents?}

\section{Sample and Data}

We have deduced the demand to include immigrants from normative theories of democracy, which, in turn, have been developed with a focus on countries with established democracies and stable boundaries. This demand may have to be modified in situations in which the boundaries of a nation-state are potentially contested and its integrity endangered. Also, it seems justified that democracies that are not yet 'established' have other

\footnotetext{
${ }^{9}$ Our robustness tests show that the results of the IMIX with different weighting and aggregation schemes and only marginally change our evaluations (Blatter et al., 2015b).
} 
Table 1: The Immigrant Inclusion Index and its Components

\begin{tabular}{|c|c|c|c|}
\hline Constituent parts & Abbreviation & $\begin{array}{l}\text { Normalization } \\
\text { and scaling }\end{array}$ & Aggregation \\
\hline Citizenship rate (de facto) & DFcit_cr & $0=<90 \% / / 100=100 \%$ & \\
\hline Naturalisation rate (de facto) & DFcit_nr & $0=0 \% / / 100=10 \%<$ & \\
\hline $\begin{array}{l}\text { Alien enfranchisement rate } \\
\text { (de facto })\end{array}$ & DFae & $0=0 \% / / 100=100 \%$ & \\
\hline De facto inclusiveness & $\mathrm{DF}$ & $0-100$ & $=($ DFcit_cr + DFcit_nr + DFae $) / 3$ \\
\hline De jure access to citizenship & DJcit & ordinal scale from $0-100$ & \\
\hline De jure alien enfranchisement & t DJae & ordinal scale from $0-100$ & \\
\hline De jure inclusiveness & DJ & $0-100$ & $=(2 *$ DJcit + DJae $) / 3$ \\
\hline Immigrant Inclusion Index & IMIX & $0-100$ & $=(\mathrm{DF} * \mathrm{DJ}) \wedge 0.5 / /$ geometric mean \\
\hline
\end{tabular}

Table 2: Ordinal Classification Scheme

\begin{tabular}{ll}
\hline Very inclusive & $75.00-100.0$ \\
Fairly inclusive & $50.00-74.99$ \\
Fairly exclusive & $25.00-49.99$ \\
Very exclusive & $00.00-24.99$ \\
\hline
\end{tabular}

priorities. For such cases, we thus would have to adjust our evaluation criteria. ${ }^{10}$ This is why in our first application of the IMIX, we limit our investigation to countries which fulfil the two preconditions - and to EU Member States, since our argument only applies to them. For the first criterion, our case selection draws on the 'blueprint sample' of the Democracy Barometer, an index which was developed with a similar evaluative purpose. Taking the Polity IV and Freedom House scores as a basis, Marc Bühlmann and his colleagues compiled a sample of 30 countries that can be considered to be the most established democracies in the world (all those that have consistently perfect scores from 1995-2005 on both indices; see Bühlmann et al., 2012, p. 527). Within the group of established democracies in the EU, however, we exclude the Baltic States since they do not sufficiently fulfil our second precondition. Combined with the overlap of all data sources, this selection allows us to cover a cross-section of 20 EU Member States (see below), with data clustering around 2010. As indicated above, we could draw on databases by EUDO CITIZENSHIP for measuring the de jure components. For the de facto components, we collected data from Eurostat, ${ }^{11}$ the European Social Survey (ESS, 2010) and official country statistics.

\section{Results}

To interpret our results, we craft the following classification scheme (Table 2). It linearly divides the range of the IMIX scale into four categories that numerically and linguistically reflect the underlying concept of electoral inclusiveness. The differences in absolute values are still interpretable as more or less inclusive, but the overall attribution of our

\footnotetext{
${ }^{10}$ For a discussion of how the IMIX can be expanded to other countries see Blatter et al., 2015b, pp. 46-47.

${ }^{11}$ See tiny.cc/eustat_migration (22 December 2015).
} 
Table 3: Results

\begin{tabular}{|c|c|c|c|c|c|c|c|c|c|c|c|c|}
\hline Country & Category & $I M I X$ & $D F$ & DJ & DFcit_cr & DFcit_nr & DFae & DJcit & DJae & $\begin{array}{c}D F \\
E U \%\end{array}$ & $\begin{array}{c}D J \\
E U \%\end{array}$ & $\begin{array}{l}I M I X \\
-E U\end{array}$ \\
\hline SE & fairly & 62.77 & 67.44 & 58.42 & 50.28 & 97.85 & 54.19 & 62.63 & 50.00 & 19.72 & 14.26 & 52.08 \\
\hline FI & inclusive & 58.40 & 56.85 & 60.00 & 76.40 & 47.42 & 46.73 & 65.00 & 50.00 & 24.65 & 13.88 & 47.05 \\
\hline NL & & 55.00 & 57.26 & 52.83 & 62.04 & 58.70 & 51.04 & 54.24 & 50.00 & 23.91 & 15.77 & 44.03 \\
\hline $\mathrm{BE}$ & & 54.97 & 44.39 & 68.07 & 20.87 & 52.06 & 60.22 & 78.36 & 47.50 & 33.89 & 12.24 & 41.87 \\
\hline UK & & 54.75 & 49.25 & 60.87 & 42.35 & 61.25 & 44.15 & 68.65 & 45.31 & 12.25 & 12.32 & 48.03 \\
\hline HU & & 52.38 & 58.29 & 47.08 & 83.26 & 50.68 & 40.92 & 48.12 & 45.00 & 16.96 & 15.92 & 43.77 \\
\hline PT & & 51.41 & 43.94 & 60.14 & 65.70 & 58.90 & 7.23 & 76.61 & 27.20 & 0.90 & 5.54 & 49.74 \\
\hline FR & fairly & 46.01 & 35.94 & 58.89 & 48.29 & 54.06 & 5.47 & 77.08 & 22.50 & 5.08 & 12.73 & 41.87 \\
\hline IE & exclusive & 44.06 & 29.21 & 66.46 & 23.07 & 19.86 & 44.71 & 74.69 & 50.00 & 23.05 & 12.53 & 36.15 \\
\hline MT & & 41.85 & 48.18 & 36.34 & 62.89 & 55.88 & 25.78 & 49.52 & 10.00 & 17.84 & 9.17 & 36.15 \\
\hline SI & & 41.17 & 32.18 & 52.66 & 58.77 & 28.87 & 8.91 & 56.49 & 45.00 & 6.67 & 15.82 & 36.49 \\
\hline PL & & 38.09 & 49.54 & 29.28 & 98.71 & 49.29 & 0.63 & 39.76 & 8.33 & 0.42 & 9.48 & 36.16 \\
\hline DK & & 37.85 & 45.85 & 31.25 & 48.89 & 26.16 & 62.50 & 21.87 & 50.00 & 26.69 & 26.66 & 27.75 \\
\hline IT & & 30.36 & 24.25 & 37.99 & 49.76 & 20.98 & 2.02 & 49.91 & 14.17 & 2.78 & 12.42 & 28.01 \\
\hline DE & & 27.08 & 19.89 & 36.87 & 19.41 & 19.55 & 20.70 & 46.93 & 16.75 & 34.70 & 15.14 & 20.16 \\
\hline $\mathrm{CZ}$ & & 26.42 & 27.10 & 25.76 & 58.07 & 4.50 & 18.71 & 34.89 & 7.50 & 23.02 & 9.70 & 22.03 \\
\hline LU & & 24.67 & 10.49 & 58.06 & & & 12.40 & 65.84 & 42.50 & 25.42 & 11.48 & 20.05 \\
\hline ES & exclusive & 23.77 & 11.70 & 48.29 & 4.76 & 24.17 & 6.18 & 58.52 & 27.83 & 16.73 & 11.50 & 20.41 \\
\hline AT & & 23.29 & 23.04 & 23.55 & 19.49 & 23.98 & 25.65 & 29.74 & 11.17 & 37.11 & 15.80 & 16.95 \\
\hline CY & & 21.52 & 13.73 & 33.71 & 0.00 & 38.12 & 3.0 & 46.40 & 8.33 & 7.47 & 8.24 & 19.83 \\
\hline mean & $\begin{array}{l}\text { fairly } \\
\text { exclusive }\end{array}$ & 40.79 & 37.43 & 47.33 & 44.65 & 40.57 & 27.06 & 55.26 & 31.45 & 17.96 & 13.03 & 34.43 \\
\hline
\end{tabular}

IMIX = Immigrant Inclusion Index; DF = de facto inclusiveness; DJ = de jure inclusiveness; DFcit_cr = citizenship rate; DFcit_nr = naturalization rate; DFae = enfranchisement rate; DJcit $=$ de jure access to citizenship; DJae = de jure alien enfranchisement; DF EU \% = percent 'EU support' for de facto inclusiveness; DJ EU \% = percent 'EU support' for de jure inclusiveness; IMIX - EU = IMIX without 'EU support'; the results are visualized in appendix III.

normative verdict can only be reached with this ordinal classification. The decision to use a linear division with 50 as the midpoint is due to the fact that four out of five (sub-)components of the index are either (rescaled) percentages (all de facto measures) or de jure measures (alien enfranchisement) that plausibly reflect this scaling.

The first and main result of our study is the stark discrepancy between the laws and practice of electoral inclusion in established European democracies and the ideal of 'universal suffrage' (Table 3). Sweden comes nearest to being a 'very inclusive' democracy, but still falls into the 'fairly inclusive' category by a large margin. It achieves the good rating because it has similarly high scores in the de facto and the de jure dimensions. Its neighbour Finland is similar, albeit at a slightly lower level. The third Scandinavian country, Denmark, does not perform nearly as well, falling into the 'fairly exclusive' category. Belgium, and especially the UK and Portugal are 'fairly inclusive' democracies primarily because their laws are rather inclusive; in practice, they are much more exclusive. The gap between the de jure and the de facto score is even more pronounced for Ireland, Luxembourg and Spain. The latter two countries are placed at the lower end of the IMIX rating because they exclude many immigrant residents in practice. Nevertheless, in contrast to Austria, Cyprus, Italy, Germany and the Czech Republic, their citizenship and 
voting regulations do not seem to be the main causes for this problematic situation, indicating a comparatively higher willingness to include immigrants. The situation in Hungary and the Netherlands, and to a lesser extent in Malta and Poland, is characterized by the fact that the de jure scores are much lower than the de facto scores. Their fairly exclusive or very exclusive laws do not (yet) have similarly strong exclusive consequences in practice.

Our second important finding is that in European democracies there is a tendency not to use alien voting rights as an alternative to naturalization or as a compensation for not granting early access to citizenship. Those who provide their non-citizens with voting rights also tend to have inclusive access to citizenship (for de jure components: Spearman's $\rho=0.45$; for de facto components: $\rho=0.23$ ). ${ }^{12}$ This finding of a moderately positive correlation is in line with previous studies on the empirical relationship of laws regulating the access to citizenship and alien enfranchisement (Huddleston and Vink, 2015). Furthermore, our results show that for the overall electoral inclusiveness, the role of enfranchising aliens is most indicative. The first six countries on the IMIX scale score exceptionally high on alien enfranchisement; and there are only two countries that reach a score in the upper half of the IMIX without introducing alien voting rights beyond non-national EU citizens (France and Malta). Furthermore, we can observe that those countries with exclusive citizenship laws usually do not allow all aliens to vote either; Denmark is a remarkable exception. Hence, it seems that the introduction of alien voting rights beyond EU citizens signals the general willingness of a country to include immigrant residents into the demos.

As a third result we want to highlight the positive function of EU membership. According to EU law, EU members must grant voting rights to non-national EU citizens in local legislative elections (voting rights for local mayoral elections and referenda are optional, but recommended, which is why we treat these aspects also as parts of 'EU support' ${ }^{13}$; for details see appendix IIa, IIb, IIc, and IId). ${ }^{14}$ Two countries would have to be classified as 'very exclusive' if they were not EU members. Germany and the Czech Republic reach the threshold for being classified as 'fairly exclusive' instead of 'very exclusive' only because they implement EU law (see the last column of Table 3, which displays the IMIX score 'without EU support'). And Luxembourg and Spain would only barely make it above the 'fairly exclusive' threshold without EU membership. The proportion of 'EU support' even gets as large as 37 per cent in the case of Austria's de facto score; and without it, Austria would be much more exclusive. In consequence, the EU should be recognized as the institution that guarantees a minimum of electoral inclusiveness within its Member States.

But not only the least inclusive European democracies get a boost in inclusiveness through EU membership. When looking at Table 3, one can easily see that almost all countries that fall into the 'fairly inclusive' category are greatly aided in achieving this label by applying the EU law. For instance, Belgium's de facto score is 34 per cent due to enfranchised non-national EU citizen residents; and only Sweden would still remain in the 'fairly inclusive' category if 'EU support' was subtracted from the IMIX score. We thus conclude that the EU plays an important democracy-enhancing role when it comes to immigrants' electoral inclusion in EU Member States.

\footnotetext{
12 Correlations of all (sub-)components and some further disaggregated analyses are documented in the appendix V and VI.

${ }^{13}$ We talk about 'EU support' and not about an 'EU effect' in order to signal that we do not claim a causal role for the EU in each country, but a functional role as a safeguard in all countries (see below). Furthermore, we do not take into account the indirect consequences of EU membership for national citizenship and electoral laws, which certainly exist as well (see, for example, Triandafyllidou and Gropas, 2014).

${ }^{14}$ This is mandated by Council Directive 94/80/EC, 1994 OJL 368/38, December 19, 1994.
} 
One might correctly point to the fact that in some European countries, it was not the EU, but another European institution that stimulated a more adequate inclusion of immigrants into the demos. The three Nordic states (Sweden, Finland and Denmark) as well as the Netherlands have all ratified the Council of Europe Convention on the Participation of Foreigners in Public Life at Local Level - the "most pertinent international instrument in this field' (Lansbergen and Shaw, 2010, p. 51). This is why they all exhibit perfect scores for the de jure alien enfranchisement on the local level. Hence, one may argue that it might not be correct to gratify the EU for making these countries more inclusive. Nevertheless, within our normative analysis, we still argue that part of their good score is due to membership of the EU. Even if it is true that the inclusion of immigrants in these countries has been the consequence of their ratification of the Council of Europe Convention, it is EU membership that makes this inclusion sticky. Nation-states are sovereign in ratifying but also withdrawing from international conventions. In contrast, as EU members they cannot unilaterally decide to change or not to implement the mandatory EU acquis - they could only decide to leave the EU. In times when many European nationstates act autonomously and egoistically in dealing with the refugee crisis, this difference can be crucial. This again highlights the role of the EU as a safeguard to provide a minimum of democratic inclusiveness for immigrants.

Since the IMIX is evaluative in its approach, we want to justify some potentially controversial conceptual decisions once more in light of these results. First, we address the question of whether it is acceptable to include the citizenship rate as a criterion for assessing the inclusiveness of democracies since it punishes countries which are rather open when it comes to immigration. Second, some results make clear why our decision to take both the de facto and the de jure understanding of inclusiveness into account is important for an evaluative account (while for causal analysis we do not recommend to use the fully aggregated IMIX).

In our assessment of the de facto situation, countries with high immigration rates (like Spain or Switzerland) score low partly because we included the citizenship rate as an indicator for access to citizenship. Given the fact that today non-citizen residents that have been granted a legal resident status in the territory of an established democracy enjoy many other political as well as civic, social and economic rights (Soysal, 1994), the inclusion of this indicator might be questionable. However, for several reasons, we think our decision is correct in the context of the debate on democratic deficits. First of all, it must be noted again that with our measurement we only cover long-term immigrants who have resided in a country for five years, and thus our normative demand indeed only applies to them. Second, the IMIX reveals the fact that some countries are rather open when it comes to letting foreigners work and live on their territory, but they are not open when it comes to giving those people a voice in making the rules they have to obey. From a normative point of view, having an open immigration policy cannot provide an excuse for excluding immigrant residents from the demos in the long run - at least if these democracies want to be worth their name. Third, the joint presentation of the citizenship rate with the naturalization rate and the alien enfranchisement rate highlight the fact that some countries (like Belgium) are able to substantially reduce the democratic deficit that comes with a low citizenship rate, whereas many others are not. Furthermore, the joint presentation of the de facto and the de jure scores reveals that some countries (like Spain) show some willingness to reduce the gap between the population and the demos, 
whereas other countries (like Austria) do not. Nevertheless, we share the conviction that other political rights and non-electoral forms of inclusion should be taken into account in a more comprehensive assessment of democracies. If we assume that other forms of inclusion (such as providing immigrants a voice through representative councils) are acceptable substitutes for their electoral inclusion - and only under this, highly questionable, assumption - the democratic deficit of many national democracies might be less pronounced than we currently diagnose.

Some readers might question the inclusion of the de facto dimension in our assessment tool altogether. They could draw on our argument that the rates that we measure are caused by too many factors beyond the control of nation-states. However, the case of Portugal shows that an analysis of the laws alone might be misleading. When we look at the laws, Portugal seems to be very generous in granting alien voting rights, but this does not translate into large numbers of enfranchised immigrants. Case studies like Pedroza (2013) help us to understand why this is so. But for a quantitative assessment tool, the most pragmatic solution is to take both understandings into account. The case of Poland illustrates best why examining the numbers alone is equally misleading. In our overall assessment Poland reaches a 'fairly exclusive' rating mainly because of its very high citizenship rate, which in turn mirrors the fact that Poland does neither attract nor allow many immigrants. But since Polish citizenship laws are exclusive and aliens are not enfranchised, the inclusion of the de jure dimension indicates a low willingness to be inclusive. Only if we take both dimensions into account can we reach an accurate and fair assessment of Poland's electoral inclusiveness.

\section{Summary and Conclusion}

Based on an 'overlapping consensus' within normative theories of democracy, we have developed the Immigrant Inclusion Index (IMIX) as a measurement tool that is tailormade for assessing how well established democracies comply with the normative demand for including long-term immigrant residents. Taking into account both pathways for inclusion into the demos - access to citizenship and alien enfranchisement - and both de facto as well as de jure understandings of inclusiveness, we have systematically documented and evaluated the current situation in 20 European democracies. Our evaluation reveals how far away European democracies are from granting truly 'universal suffrage'. Even those countries with the highest scores still show substantial shortcomings when it comes to including immigrant residents.

In times when the EU faces an unprecedented legitimacy crisis and when many claim that the EU suffers from and produces democratic deficits on the national level, it seems important to reveal that European nation-states have their own fundamental democratic deficits. These pronounced democratic deficits within EU Member States with respect to inclusion do not reduce the democratic deficits of the EU, but they relativize the often proclaimed superiority of national democracies. Even more, our analysis shows that the EU plays an important role in reducing this democratic deficit. Together with the Council of Europe, it has stimulated the inclusion of immigrants into national and local demoi, and it serves as a safeguard for nation-states not to fall below a minimum when it comes to including resident immigrants. 
This study also complements our previous knowledge on the democracy-enhancing function of the EU, since until now this positive role of the EU has been acknowledged primarily for the transition towards stable democracies. Furthermore, with our focus on the fundamental aspect of inclusion, we add a new facet to the argument that the embedding in international or multilateral institutions strengthens liberal democracy within established democracies (Keohane et al., 2009). On the other hand, however, we should not forget that, in contrast to the Council of Europe, the EU has not done much to facilitate the political inclusion of third-country nationals on either the European or the national level. In this respect, negative verdicts such as the one of Andrew Geddes (1995) are still accurate.

We would like to conclude with a more methodological note. Our results are very much in line with the findings of other studies. For example, with regard to the access to citizenship, the factor of so-called Nordic regime type has also been highlighted by Janoski (2010). Taken together with the aspect of colonial background, the results of the IMIX (including the exceptional cases of Spain and Denmark) therefore confirms similar studies (Howard, 2009; Janoski, 2010). Finally, the fact that Germany and Austria cluster at the low end of the IMIX spectrum lends support to the widespread assumption that former Gastarbeiterländer have exclusive citizenship. In fact, the IMIX is highly (and significantly; $p$-values not shown) correlated with both the Citizenship Policy Index (CPI) introduced by Howard $(2009 ; \rho=0.70)$, the index introduced by Koning (2011; $\rho=0.70$ ), and the individual equality dimension of the Index of Citizenship Rights for Immigrants (ICRI) presented by Koopmans and Michalowski $(2016 ; \rho=0.81)$ - indices that share a large overlapping population of countries with the IMIX. ${ }^{15}$ However, since the correlation with the de facto dimension is much weaker for all indices $(\rho=0.32$ for CPI; $\rho=0.42$ for Koning; $\rho=0.51$ for ICRI), the IMIX adds something new. This is also evidenced by the positive but moderate correlation with the aggregate MIPEX $(\rho=0.54)$, another index widely used in the field. We are aware that this field seems saturated with many other indices, and that previous overviews have called for expanding the coverage of existing indices rather than creating new ones (Helbling, 2013). Nevertheless, we are convinced that the IMIX - which builds on existing indicators such as CITLAW and ELECAW - still presents a valuable complement. Empirically, our index contains new and original data, especially with respect to the alien enfranchisement rate, for which we have conducted extensive independent data collection. And conceptually, we are the first who systematically discuss and theorize the differences between a de jure and a de facto understanding of a measurement concept. Finally, the IMIX embodies the first truly normative evaluation of the electoral inclusion of immigrants. This does not only mean that all its elements have been conceptualized, measured and aggregated with this particular goal in mind, but also that the results have been analyzed and interpreted accordingly. We take the strong overlap with findings from other studies and indices, which were executed with an explanatory and not an evaluative goal in mind, as a sign of the validity of our empirical findings. But we also want to point to a major difference: Whereas explanatory studies focus on variation, normative studies are concerned with

\footnotetext{
15 The study by Koopmans and Michalowski (2016, p. 31) even used an earlier version of the IMIX (Blatter et al., 2015b) as an external validity test for the individual equality dimension of the ICRI. They report a Pearson correlation coefficient of $p=0.79$.
} 
absolute values. We think the latter is more adequate when it comes to normative debates like those on democratic deficits - and this should be more recognized within the methodological discourse on concept formation and index-building.

Correspondence:

Joachim Blatter

University of Lucerne

Lucerne, Switzerland

email: joachim.blatter@unilu.ch

\section{References}

Barber, B.R. (2003 [1984]) Strong Democracy (Berkeley, CA: University of California Press). Bauböck, R. (1998) 'Sharing History and Future?' Constellations, Vol. 4, No. 3, pp. 320-345. Bauböck, R. (2003) 'Reinventing Urban Citizenship'. Citizenship Studies, Vol. 7, No. 2, pp. 139-160.

Bauböck, R. (ed) (2010) 'Dual citizenship for transborder minorities? How to respond to the Hungarian-Slovak tit-for-tat'. EUI Working Paper RSCAS No. 2010/75 (Florence: Robert Schuman Centre for Advanced Studies).

Bauböck, R. (2015) 'Morphing the Demos into the right shape'. Democratization, Vol. 22, No. 5, pp. 820-839.

Bauböck, R. and Joppke, C. (eds.) (2010) 'How liberal are citizenship tests?' EUI Working Papers RSCAS No. 2010/14 (Florence: Robert Schuman Centre for Advanced Studies).

Bauböck, R., Honohan, I., Huddleston, T., Hutcheson, D., Shaw, J. and Vink, M. P. (2010) 'Access to Citizenship and its Impact On Immigrant Integration. European Summary and Standards.' Available online at: http://cadmus.eui.eu/bitstream/handle/1814/29828/ AccesstoCitizenshipanditsImpactonImmigrantIntegration.pdf? sequence $=1$. Last accessed: 27 September 2016.

Beckman, L. (2009) The Frontiers of Democracy (Basingstoke, UK: Palgrave Macmillan).

Beckman, L. and Erman, E. (2012) 'Introduction'. In Beckman, L. and Erman, E. (eds) Territories of Citizenship (Basingstoke: Palgrave Macmillan), ix-xviii.

Benhabib, S. (2004) The Rights of Others (Cambridge: Cambridge University Press).

Blatter, J. (2007) 'Legitimacy'. In Bevir, M. (ed.) Encyclopedia of Governance (Thousand Oaks, CA: Sage), 518-521.

Blatter, J., Blättler, A. and Schmid, S. D. (2015a) 'What Happened/s To Inclusion? A Plea and Three Proposals for Closing the Gap Between Democratic Theory and Empirical Measurement of Democracies'. IPSA Committee on Concepts and Methods Working Papers Series on Political Concepts, No. 64. Available online at http://www.concepts-methods.org/Files/WorkingPaper/ PC\%2064\%20Blatter\%20et\%20al.\%20(2015).pdf Last accessed: 27 September 2016.

Blatter, J., Schmid, S. D. and Blättler, A. (2015b) 'The Immigrant Inclusion Index (IMIX). A Tool for Assessing the Electoral Inclusiveness of Democracies with Respect to Immigrants'. Working Paper Series Global Governance and Democracy, No. 8, 2nd edition, (Switzerland: Department of Political Science, University of Lucerne). Available online at: https://www. unilu.ch/fileadmin/fakultaeten/ksf/institute/polsem/WP8_The_Immigrant_Inclusion_Index_ Second_Edition_2015.pdf. Last accessed: 27 September 2016.

Bosniak, L. (2006) The Citizen and the Alien (Princeton, NJ: Princeton University Press).

Bühlmann, M., Merkel, W., Müller, L. and Wessels, B. (2012) 'The Democracy Barometer. A New Instrument To Measure the Quality of Democracy and its Potential for Comparative Research'. European Political Science, Vol. 11, No. 4, pp. 519-536. 
Carens, J.H. (2010) Immigrants and the Right To Stay (Cambridge, MA: MIT Press).

Carens, J.H. (2013) The Ethics of Immigration (Oxford: Oxford University Press).

Coppedge, M., Gerring, J., Lindberg, S.I., Teorell, J. et al. (2014) 'Varieties of Democracy Methodology v3'. Available online at: https://v-dem.net/DemoComp/en/images/ VDemMethodologyv3.pdf. Last accessed: 10 April 2016.

Crombez, C. (2003) 'The Democratic Deficit in the European Union. Much Ado about Nothing?' European Union Politics, Vol. 4, No. 1, pp. 101-120.

Dahl, R.A. (1971) Polyarchy (New Haven: Yale University Press).

Dahl, R.A. (1989) Democracy and its Critics (New Haven: Yale University Press).

Dahl, R.A. (2000) On Democracy (New Haven: Yale University Press).

EMN (2011) 'Temporary and Circular Migration'. Available online at: http://ec.europa.eu/dgs/ home-affairs/what-we-do/networks/european_migration_network/reports/docs/emn-studies/ circular-migration/0a_emn_synthesis_report_temporary_circular_migration_final_sept_ 2011_en.pdf. Last accessed: 27 September 2016

ESS (2010) 'European Social Survey Round 5. Data file edition 3.0' (Norway: Norwegian Social Science Data Services, Norway - Data Archive and distributor of ESS data).

EUDO CITIZENSHIP Observatory (2015) 'ELECLAW Indicators. Version 2.0' (San Domenico di Fiesole: European University Institute).

Fick, P. (2016) ‘Does Naturalization Facilitate Integration?' Zeitschrift für Soziologie, Vol. 45, No. 2, pp. 107-121.

Geddes, A. (1995) 'Immigrant and Ethnic Minorities and the EU's 'Democratic Deficit'. JCMS, Vol. 33, No. 2, pp. 197-217.

Goertz, G. (2006) Social Science Concepts (Princeton, NJ: Princeton University Press).

Helbling, M. (2013) 'Validating Integration and Citizenship Policy Indices'. Comparative European Politics, Vol. 11, No. 5, pp. 555-576.

Howard, M.M. (2009) The Politics of Citizenship in Europe (New York: Cambridge University Press).

Huddleston, T. and Vink, M.P. (2015) 'Full Membership or Equal Rights? The Link Between Naturalisation and Integration Policies for Immigrants in 29 European States'. Comparative Migration Studies, Vol. 3, No. 8, pp. 1-19.

Human Rights Watch (1998) 'Losing the Vote. The Impact of Felony Disenfranchisement Laws in the United States'. Available online at: http://www.sentencingproject.org/doc/file/fvr/ fd_losingthevote.pdf. Last accessed: 10 April 2016.

Janoski, T. (2010) The Ironies of Citizenship (Cambridge: Cambridge University Press).

Jensen, T. (2009) 'The Democratic Deficit of the European Union'. Living Reviews in Democracy, Vol. 1, pp. 1-8.

Keohane, R.O., Macedo, S. and Moravcsik, A. (2009) 'Democracy-Enhancing Multilateralism'. International Organization, Vol. 63, pp. 1-31.

Klaus, V. (2014) 'In Defence of the Nation-State'. Policy, Vol. 30, No. 3, pp. 3-7.

Koning, E.A. (2011) 'Ethnic and Civic Dealings with Newcomers: Naturalization Policies and Practices in Twenty-Six Immigration Countries'. Ethnic and Racial Studies, Vol. 34, No. 11, pp. 1974-1994.

Koopmans, R. and Michalowski, I. (2016) 'Why Do States Extend Rights to Immigrants? Institutional Settings and Historical Legacies Across 44 Countries Worldwide'. Comparative Political Studies, online first, pp. 1-34.

Lansbergen, A. and Shaw, J. (2010) 'National Membership Models in a Multilevel Europe'. International Journal of Constitutional Law, Vol. 8, No. 1, pp. 50-71.

Miller, D. (2008) 'Immigrants, Nations, and Citizenship'. Journal of Political Philosophy, Vol. 16, No. 4, pp. 371-390. 
Munck, G.L. (ed.) (2009) Measuring Democracy (Baltimore, MD: Johns Hopkins University Press).

OECD (2008) 'International Migration Outlook, Part III - Return Migration: A New Perspective' Available online at: https://www.oecd.org/migration/mig/43999382.pdf. Last accessed: 27 September 2016

Owen, D. (2013) 'Citizenship and the Marginalities of Migrants'. Critical Review of International Social and Political Philosophy, Vol. 16, No. 3, pp. 326-343.

Paxton, P., Bollen, K.A., Lee, D.M. and Kim, H. (2003) 'A Half-Century of Universal Suffrage: New Data and a Comparative Analysis'. Studies in Comparative International Development, Vol. 38, No. 1, pp. 93-122.

Pedroza, L. (2013) 'Policy Framing and Denizen Enfranchisement in Portugal'. Citizenship Studies, Vol. 17, No. 6-7, pp. 852-872.

Pettit, P. (2012) On the People's Terms (Cambridge: Cambridge University Press).

Rawls, J. (1987) 'The Idea of an Overlapping Consensus'. Oxford Journal of Legal Studies, Vol. 7 , No. 1, pp. 1-25.

Rubio-Marin, R. (2000) Immigration as a Democratic Challenge (Cambridge: Cambridge University Press).

Ruhs, M. (2013) The Price of Rights (Princeton, NJ: Princeton University Press).

Schimmelfennig, F. and Scholtz, H. (2008) 'EU Democracy Promotion in the European Neighbourhood'. European Union Politics, Vol. 9, No. 2, pp. 187-215.

Schmid, S. D., Arrighi, J.-T. and Bauböck, R. (2015) ELECLAW Indicators: Measuring Voting and Candidacy Rights of Resident Citizens, Non-Resident Citizens and Non-Citizen Residents. Version 2.0'. EUDO CITIZENSHIP Observatory, San Domenico di Fiesole: European University Institute.

Schmidt, V.A. (2006) Democracy in Europe (Oxford: Oxford University Press).

Soysal, Y.N. (1994) Limits of Citizenship (Chicago: University of Chicago Press).

Triandafyllidou, A. and Gropas, R. (2014) European Immigration: A Sourcebook (Aldershot: Ashgate).

Vink, M.P. and Bauböck, R. (2013) 'Citizenship Configurations: Analysing the Multiple Purposes of Citizenship Regimes in Europe'. Comparative European Politics, Vol. 11, No. 5, pp. 621-648.

Walzer, M. (1983) Spheres of Justice (New York: Basic Books).

\section{Supporting Information}

Additional supporting information can be found in the online version of this article at the publisher's website:

\section{Documentation of indicator selection, coding and aggregation}

a. De jure access to citizenship (DJcit)

b. De jure alien enfranchisement (DJae)

c. De facto access to citizenship (citizenship rate and naturalization rate / DFcit)

d. De facto alien enfranchisement (alien enfranchisement rate / DFae)

II. Estimating 'EU support'

a. 'EU support' as part of de jure alien enfranchisement

b. 'EU support' as part of de facto alien enfranchisement

c. Estimating 'EU support' for the IMIX

d. Disaggregated data for 'EU support' 
Table 1A: Data on 'EU support'

III. Results as graphs

Figure 2A: De jure inclusiveness

Figure 3A: De facto inclusiveness

Figure 4A: The IMIX and its dimensions

IV. Alternative results

Table 2A: Alternative results

V. Correlations of all of all (sub-)components, dimensions, and the IMIX

Table 3A: Spearman correlation matrix

VI. Varieties of electoral inclusiveness with respect to immigrants - some country spiders 